\title{
La donación de la biblioteca del arzobispo Bartolomé María de las Heras (1805-1823) al Seminario Santo Toribio, en vísperas de la independencia del Perú
}

José Antonio Benito

Universidad Católica Sedes Sapientiae

José Agustín de la Puente Candamo dio a conocer en 1955 la relación de libros de la biblioteca de Bartolomé María de las Heras. ${ }^{1}$ Se trataba del primer inventario conocido acerca de tan decisivo arzobispo y fue realizado en 1791, cuando este prelado era recién nombrado obispo del Cusco. Con motivo de mi investigación sobre el Seminario de Santo Toribio iniciada en 1999, di a conocer un segundo inventario -realizado unos años después, en 1816- que ahora publico íntegramente. Han pasado 63 años desde que Mercurio Peruano presentó la que se puede considerar primera biblioteca del prelado y en este momento se publica la relación de la que se puede considerar como su definitiva biblioteca.

Con motivo de los cien años de la revista y en vísperas del bicentenario considero muy oportuno presentar la singular trayectoria de monseñor Bartolomé María de las Heras, quien fue el último prelado limeño del virreinato y el primero de la independencia. Nacido en Sevilla (1743) y muerto en Madrid (1823), vivirá en el Perú desde 1786, en que llega como canónigo a Huamanga, hasta 1822, en que presenta su dimisión ante la hostilidad del gobierno independentista.

Son 36 años decisivos en la historia patria y que el prelado vive con prudencia y responsabilidad. Uno de los medios para aproximarnos a las fuentes en las que se nutre su pensamiento nos lo brinda su biblioteca personal. La presente en el archivo del Seminario de Santo Toribio tiene por título: Índice manual de los libros que donó a este Real Seminario de Santo Toribio el Excelentísimo e Ylustrísimo Señor Doctor Don Bartolomé María de las Heras, su especial Mecenas.

José Agustín de la Puente Candamo, “Sobre la biblioteca de Bartolomé María de las Heras". Mercurio Peruano, 337, 1955, pp. 297-300.

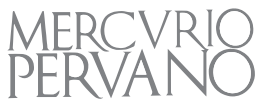




\section{Semblanza de un obispo ilustrado}

Nació en Carmona (Sevilla) el 25 de abril de 1743. Sus padres fueron Leopoldo de las Eras Navarro y Gregoria de Ortega Morillo, quienes se habían casado siete años antes, en 1736, y provenían de familias de mediana posición económica. Su padre era alguacil mayor y recaudador de las rentas reales en Carmona, y su abuelo Bartolomé de las Eras Navarro fue regidor perpetuo del cabildo. Bautizado cinco días después, recibió cuatro nombres: Bartolomé, María, Marcos y José. Era el único hijo varón, pues tan solo tuvo dos hermanas menores: María Dolores de la Era, desposada con Francisco González, y Bárbara de las Eras, casada con Manuel Giménez Lorite.

Estudió en el colegio de los jesuitas de Sevilla, y se graduó en Derecho y se doctoró en Cánones y Teología en Toledo. En Sevilla perteneció al colegio de abogados, al tiempo que ostentaba un beneficio en Cazalla de la Sierra. Marchó a la corte, y se convirtió en capellán de honor y predicador de Carlos III, y fue además examinador sinodal y vicario general de los ejércitos y de la armada. Cargos todos ellos que desempeñó hasta su nombramiento como deán en la diócesis de Huamanga en el Perú.

Arriba al Perú con el nombramiento de deán de la catedral de Huamanga en 1786, cargo que ocupó solo durante un año. Pronto, y en atención a sus méritos, se le consagra obispo del Cusco el 12 de octubre de 1790, en los difíciles años tras la revuelta de Túpac Amaru, para pacificar el tempestuoso territorio. La ceremonia de ordenación episcopal se realizó en la catedral de Arequipa a cargo del ilustre prelado Pedro José Chávez de la Rosa al filo del nuevo año de 1791. El nuevo pastor ocupa su sede del Cusco, donde su acción apostólica duraría 15 años.

De este tiempo es el inventario de bienes referido, fechado en el Cusco el 16 de marzo de 1791, que tiene por objetivo dejar bien transparentes sus propiedades:

Testimonio de los bienes inventariados a pedimento del ilustrísimo señor doctor don José Bartolomé María de las Heras, dignísimo obispo de esta diócesis, para que por su fallecimiento o por omisión de dicho señor obispo, no sean vejados ni molestados sus herederos cuando reclamen los bienes que adquirió antes del ingreso a la Mitra.

Su primera visita pastoral tuvo una duración de cuatro años (1792-1795), y llegó a pie o en cabalgaduras a los poblados más inaccesibles de sus diócesis. La visita abarcó 116 doctrinas o pueblos de indios, en la que urgió a los curas y doctrineros la reparación y el aseo de los templos y las capillas, y normó que ningún cura se ausentase de su doctrina sin licencia del prelado. A él se debe el altar de plata de la catedral del Cusco. Levantó 28 templos. 
Tuvo por familiar de confianza al sacerdote Nicolás Tadeo Gómez, paisano suyo, nacido en Marchena (Sevilla) en 1785 y fallecido en Córdoba en 1834, quien lo acompañó por más de 27 años. Gracias a su diario podemos conocer el esplendor borbónico en Chile y el Perú; la sociedad aristocrática, adinerada, también la religiosa, la del regalismo. ${ }^{2}$

En Santiago fue contable de una compañía comercial y en Lima entró en la élite criolla por su 'parentesco' con los Salazar y Carrillo. Fue comerciante en las minas de Pasco, hasta que el arzobispo González de la Reguera lo ordenó sacerdote y lo nombró profesor de latín del Seminario de San Carlos. Fue en el Cusco donde trabó contacto con monseñor Bartolomé María de las Heras, y regresó a Lima cuando De las Heras fue nombrado arzobispo.

Ante el fallecimiento del arzobispo de Lima, Juan Domingo González de la Reguera, en 1805, queda vacante la sede principal del virreinato, por la que el rey Carlos IV hizo la consabida 'presentación', y designó a Bartolomé de las Heras, por lo tanto, como XVII arzobispo de Lima. Se despidió de sus fieles, y -en clima ya inminente de emancipación- les pidió que guardaran fidelidad al rey, lo que habrá que tener en cuenta para explicar el cambio cuando, ya en Lima, ante los hechos consumados, firme el acta de independencia.

Los años limeños fueron los de José de Abascal, época brillante pero también de tensiones sociales y políticas, que él vivió con intensidad como decidido partidario de Fernando VII. Es consciente del complejo periodo a caballo entre el virreinato y la gestación de la República independiente, con la entrada de San Martín en Lima, y que él debe sufrir como penoso calvario y cirineo de su amado arzobispo desterrado. Su secretario y cronista, Nicolás Tadeo Gómez, fue un observador curioso y metódico que dispuso de una atalaya extraordinaria y que no escribió por oficio, sino por satisfacer su propia inquietud; pero desde la perspectiva de un protagonista que se movió siempre en posiciones privilegiadas. Cuando llegó con monseñor Bartolomé de las Heras a Lima escribió:

Seis meses me llevaron estos señores viendo las grandezas de Lima. Quedé absorto al ver aquellos templos, la opulencia y riqueza de tantas alhajas de oro, plata y diamante, ornamentos, música, voces y devoción de todas clases de gentes. ¡Qué catolicismo! Decía yo para mí. Lo que más me admiró fue tanta plata, pues las andas de los Santos Patriarcas de las religiones, [eran] todas de plata maciza; las de Nuestra Señora del Rosario, Santa Rosa y custodia de la catedral no tienen precio. Altares, retablos enteros de plata; el

\footnotetext{
2 Interesante análisis del complejo mundo religioso en el que se enfrenta la identidad católica de la sociedad arequipeña al regalismo del nuevo Estado peruano. Rolando IbERico Ruiz, La república católica dividida: ultramontanos y liberales regalistas (Lima, 1855-1860). Lima, Instituto Riva-Agüero, Pontificia Universidad Católica del Perú y Fundación M. J. Bustamante de la Fuente, 2016, 112 p.
} 
de la catedral, Santa Rosa y Nuestra Señora del Milagro, en San Francisco, se ignora su mucho costo porque se pierde el sentido en verlos y pensar en tanta grandeza y profusión. ${ }^{3}$

\section{Arzobispo de Lima}

Llegó a la capital el 17 de noviembre en medio de un extraordinario júbilo, pues era sabida la bondad y dulzura de su carácter. Su asertividad y disponibilidad para ver lo positivo de los fieles quedan manifiestas en el informe a la Santa Sede al concluir su tarea pastoral por el destierro sufrido por las nuevas autoridades independentistas:

Se admiran en la capital generalizadas ciertas virtudes que son dignas del aprecio: tales son una misericordia compasiva, una devota piedad, un gran respeto y veneración por los católicos dogmas y ministros del santuario y otros; el genio suave y dócil de las gentes de aquel país los hace sensibles a las miserias humanas; no pueden oír o ver una aflicción en el prójimo, sin que sus corazones se enternezcan; empeñan todo su poder y sus haberes por remediar una desgracia; al que ven caído lo auxilian; socorren con generosidad toda clase de necesidades; se compadecen de los enfermos, habiendo casas que, así de día como de noche, tienen medicinas y caldo pronto para los pobres que lo piden; ejercitan la limosna, y por decirlo de una vez reluce en Lima la caridad fraterna y compasiva en toda la extensión de sus objetos. ${ }^{4}$

Su celo apostólico lo llevó a largas visitas pastorales por los pueblos y anexos de la sierra. Asimismo contribuyó a erigir el cementerio general. Colaboró con todo para fundar el Colegio de Medicina de San Fernando. Mandó a reformar materialmente el Seminario de Santo Toribio, a cargo del sacerdote y arquitecto don Matías Maestro.

En 1810 impulsó y autorizó la fundación de la Casa de Ejercicios de Santa Rosa de Lima, iniciativa apostólica de la caritativa dama limeña Rosa Catalina Vásquez de Peralta, del emprendedor albacea Matías Querejazu y del emblemático arquitecto Matías Maestro. Por ella han pasado miles de personas que se han beneficiado con la práctica de los ejercicios espirituales. Hoy cumple con la doble finalidad de ser un centro de espiritualidad para retiros y ejercicios, así como un centro cultural para exposiciones y conferencias. El cabildo

\footnotetext{
3 Antonio García-Abásolo, Itinerario chileno y peruano de Nicolás Tadeo Gómez (1755-1839). De sobrecargo del navio Príncipe Carlos a mayordomo del último arzobispo español de Lima (1783-1822). Córdoba, Universidad de Córdoba, 2015, p. 98.

4 Madrid, firmado el 3 de diciembre de 1823: Relación del Arzobispado de Lima, Archivo Secreto Vaticano, Nunciatura de Madrid, 270 (ed. en P. de Leturia, Relaciones entre la Santa Sede e Hispanoamérica, 1493-1835, vol. III, Roma-Caracas, Universitas Gregoriana-Sociedad Bolivariana de Venezuela, 1959-1960, pp. 206-227).
} 
catedralicio la regenta y ofrece a la sociedad como centro cultural católica y areópago de la nueva evangelización.

En 1811 renovó la práctica del jubileo diario circular (en las iglesias de Lima). Solicitó el restablecimiento de la compañía de Jesús con fecha 29 de octubre de 1816.

Por sus méritos, la regencia de Cádiz le confirió el 26 de agosto de 1812 la Gran Cruz de la Real Orden de Carlos III y el rey Fernando VII le concedió la Gran Cruz de Isabel la Católica, el 7 de junio de 1815.

Del mismo modo, el ayuntamiento y el cabildo de Lima, en 1816, se dirigieron al rey para solicitar a la Santa Sede la dignidad cardenalicia. Parece que las gestiones del embajador de España en Roma, Marqués de Casa Irujo, quedaron paralizadas por la creciente tensión entre España y América en 1818.

\section{Su relación con el seminario:}

Tadeo Haenke, viajero inglés, describirá la Lima de nuestro protagonista en 1810, y constató acerca de los colegios:

Siguen luego los colegios nombrados de Santo Toribio y el Convictorio de San Carlos. Fundóse el primero por el santo arzobispo de aquel nombre cuando regía la silla del arzobispado de Lima, por cuya razón corre a cargo de sus sucesores. Tiene veinticuatro becas, y se enseñan en él la Filosofía, el Derecho Civil y la Teología. ${ }^{5}$

En 1810 el arzobispo De las Heras visitaba su catedral, pero, habiendo fallecido el rector Pablo Laurnaga, decidió interrumpir la visita y acercarse al seminario. El 12 de marzo comunicó al señor Nocheto, el vicerrector, la resolución que había adoptado y le pidió tuviese listos los libros de entrada y salidas de los seminaristas y pasase una nota al albacea del rector difunto a fin de que presentase las cuentas de su administrador. Nombró por consultores de la visita, según lo prescribe el Tridentino, al deán Echagüe, al tesorero y al lectoral don Ignacio Mier.

El 3 de abril pasó el arzobispo al seminario y, recibido por el cuerpo de profesores y alumnos, fue conducido a la capilla, donde hizo una exhortación a los alumnos. Luego entró en la sacristía y, advirtiendo que carecía de ornamento verde, mandó se subsanase la falta. El agua para el servicio de la casa era escasa y la estrechez del local estaba a la vista, por lo que encargó su remedio al esteta y disponible presbítero Matías Maestro.

5 E. Bartra, "Trayectoria histórica de la Facultad de Teología de Lima”, Libro anual de la Facultad de Teología Pontificia y Civil de Lima, luego Revista Teológica Limense, vol. 5, 1971, pp. 25-63, cito p. 42. 
El 4 de junio de 1810 dispuso se visitasen las capellanías morosas desde 1769. $\mathrm{Al}$ efecto libró un auto para que en el periodo de 15 días se presentasen cuantos disfrutaban de algún beneficio, con la fecha de su colación y la razón de las cargas que pesaban sobre él, y se formó expediente de todo lo actuado. Enrique Bartra constata que el seminario -en sana competencia con el Convictorio Carolino y en respuesta dócil a los deseos de su pastor- estaba preocupado por responder a las "exigencias científicas de la época elevándolos a nivel universitario". ${ }^{6}$ Se comprueba en el deseo De las Heras de dar al seminario el plan de estudios de San Carlos, ${ }^{7}$ concretado en poner "un Maestro de Latinidad y Retórica, dos catedráticos de Filosofía que deben enseñar también la historia de esta facultad y la Álgebra y Geometría tan descuidados antes, que esta es la primera vez que se oyen en los ángulos del colegio; otros tres de Teología: dogmático-escolástica, expositiva y moral, con otro de Cánones y Disciplina Eclesiástica".8

Un año más tarde gobernaba el colegio don José Silva y Olave, y como el arzobispo hubiese introducido algunas reformas en el reglamento y alguna de ellas suscitara la protesta de los seminaristas, estos presentaron un escrito respetuoso, en el que piden ser escuchados. De las Heras pidió informe al rector y este respondió el 8 de mayo de 1811. Era costumbre establecida que los alumnos salieran a sus casas los días festivos a las nueve de la mañana y la innovación introducida prescribía que la salida fuese solo en las tardes y había de hacerse en traje talar y llevando compañero. Silva y Olave no pudo menos que apoyar la pretensión de los seminaristas, pero se remitió a lo que determinase la junta conciliar. En realidad no se veía la razón de limitar la salida y sujetarla a las antedichas condiciones. Dentro de las suaves y morigeradas costumbres de las familias de entonces no se comprende que pudiera ser ocasión de tropiezo la visita de los seminaristas a los suyos. Así debió pensar el rector, pues, aun suponiendo que esta licencia ofreciese algún peligro para la vocación de los jóvenes, esto podría tener lugar en un caso particular, pero no en general. No sabemos qué determinación tomó el arzobispo, pero creemos, dada su prudencia y discreción, que debió permitir que no se alterase la costumbre.

\footnotetext{
Ibídem.

7 San Carlos influyó de modo decisivo en el Estado peruano como se evidenció en el hecho de que casi un tercio de los primeros parlamentarios peruanos eran egresados o profesores del convictorio y plasmaron su pensamiento en la Constitución de 1823. De igual modo, contribuyó a formar un clero con tendencias regalistas y liberales. Durante la independencia, su situación económica fue tan precaria que debió cerrar sus aulas por cerca de un año hasta 1822. En 1826 cambió su nombre por el de Convictorio Bolívar y fue dirigido por Manuel Lorenzo de Vidaurre, quien afianzó el regalismo y las ideas liberales. Ver Ricardo Cubas Ramacciotti, "Bartolomé Herrera como rector del Convictorio de San Carlos: desarrollo, ocaso y alcances de una reforma educativa", Mercurio Peruano, 530, 2017, pp. 120-139.

8 Informe del arzobispo don Bartolomé de las Heras sobre el seminario, fechado el 20 de diciembre de 1813; Archivo General de Indias. Audiencia de Lima 1568. Recogido en Luis A. Eguiguren, Diccionario histórico cronológico de la Universidad Real y Pontificia de San Marcos. Lima, Imprenta Torres Aguirre, 1940, vol. I, pp. 1032-1033.
} 
Más adelante, ya en España, dará buena cuenta de la situación del seminario, y destacará su trascendencia histórica, la visita realizada, el florecimiento académico, los frutos apostólicos, su encomiable y ejemplar conducta; sin embargo, al final, lamenta el "extravío" de los alumnos por abrazar la causa independentista:

Fundó el Señor Santo Toribio el Seminario Conciliar; estableció en él una arreglada constitución, mas, habiendo variado muchas cosas en el discurso de los siglos, en la visita que hice se alteraron algunos artículos y se formó un nuevo método de estudios que la experiencia ha acreditado en sus buenos efectos: florecen las ciencias sagradas en esta casa y los ejercicios y tesis (sic) públicas de los Seminaristas admiran a los literatos: hay de 70 a 80 alumnos, con el competente número de pasantes, maestros y catedráticos: la mayor parte de los instruidos que se ven en la diócesis son hijos de este Colegio: siempre han vivido con una buena conducta hasta que por los años 20 y 21 principiaron a extraviarse con la cercanía y entrada del general San Martín y con las máximas de libertad e independencia que inflamaron sus espíritus. ${ }^{9}$

\section{Tiempos revueltos por la independencia}

En 1820 comenzaron las hostilidades contra el virrey del Perú. El 7 de setiembre desembarcó en la bahía de Paracas la expedición libertadora al mando del general José de San Martín, con cuatro mil hombres a los que pronto muchos peruanos de toda condición se les unieron. Después del motín de Aznapuquio, 29 de enero de 1821, el virrey Pezuela es obligado a dimitir y se quedó al frente de las fuerzas del rey el virrey José de la Serna.

El asedio tanto por tierra como por mar puso en la situación de exigir en otras contribuciones la plata y las alhajas de las iglesias de parte del virrey en carta del 15 de febrero de 1821, a la cual el prelado responde que por razones de conciencia no le parece prudente, pues el pedido entraña un atentado a la invulnerabilidad de la Iglesia.

En junio de 1821, las tropas de San Martín estrechan el bloqueo de Lima. La Serna invita al arzobispo a unirse al ejército realista en la retirada hacia la sierra andina. A ello De las Heras responde con la negativa el 4 de julio:

Las obligaciones de un Pastor para con sus ovejas le ligan demandando a no abandonarlas en el tiempo de mayor calamidad, para velar sobre el rebaño fiado a mi cuidado, celar para que se evite la profanación de los templos y proveer de remedio espiritual a las necesidades que ocurran.

9 Pedro Leturia, Relaciones entre la Santa Sede e Hispanoamérica (1493-1835), III, Roma-Caracas 1960, p. 209. 
El 14 de julio de 1821, el general San Martín incita al ayuntamiento a convocar una junta de vecinos notables para que se expresen si la opinión general está a favor de la independencia. A la misma responde el mismo día el ayuntamiento reunido en la Sala Capitular de Lima: "Con arreglo al oficio de V.E. recibido en este momento, se queda haciendo la elección de las personas de probidad, luces y patriotismo...".

El 15 de julio el ayuntamiento adjunta el acta del cabildo de adhesión a la jura de la independencia:

Reunidos en este Excelentísimo Ayuntamiento los Señores que lo componen con el Excelentísimo e Ilustrísimo Señor Arzobispo de esta Santa Iglesia Metropolitana, prelados de los conventos religiosos, títulos de Castilla y varios vecinos de esta capital..., dijeron que la voluntad general está decidida por la independencia del Perú, de la dominación española y de cualquier otra extranjera.

Y firmaron los señores, el conde de San Isidro, Bartolomé arzobispo de Lima, y siguen nombres. A ella San Martín ese mismo día responde en referencia a las recomendables personas que fueron convocadas al cabildo abierto: "Siempre había considerado las virtudes que adornan a este ilustre vecindario; pero de aquí en adelante seré el mayor panegirista y admirador de la energía de estos habitantes, que conocen perfectamente sus verdaderos intereses".

A la declaración citada del cabildo civil de Lima le siguió la proclamación y jura de la independencia el 28 de julio de 1821. De las Heras estuvo presente en el acto y al día siguiente presidió la celebración litúrgica en la que se cantó por vez primera el tedeum en la catedral.

San Martín manifestó su reconocimiento por el valor moral que significaba tal gesto e hizo saber al arzobispo el consuelo que sentía como jefe del ejército libertador, viendo cómo el prelado contribuía a la tranquilidad pública en momentos de conflicto y continuaba siendo el baluarte de la paz, de la religión y de la moral; pero los hechos tomaron un sesgo diferente.

En el círculo de amigos de San Martín ocupaba un puesto muy elevado el argentino Bernardo Monteagudo (1790-1825). Fue su secretario y luego ministro de Guerra y Marina. Una de sus arbitrariedades consistió en la activa hostilidad contra pacíficos ciudadanos españoles, incluido el arzobispo. Por ello acusó que en la casa de ejercicios de Lima "se hacen abusos de seria trascendencia a la causa del País, empleando contra ella el venerable influjo del ministerio sacerdotal". A lo que De las Heras contestó: "Si en ellas [Las Casas de Ejercicios] se cometiera algún exceso o cualquier pretendiera turbar la paz u orden público, inmediatamente que se sepa y se tomarán las providencias correspondientes a fin de contenerlo y corregirlo". El ministro Juan García del Río influido por Monteagudo insiste el 27 de agosto en la suspensión de la Casa de Ejercicios, con tono de desafío. A ella De las Heras responde con firmeza, luego de recordarle

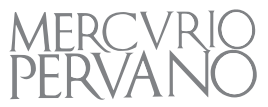


las obligaciones de un obispo y su renuncia -no hecha efectiva- del 24 de julio: "Si entonces formalicé mi renuncia por los motivos que expuse, ahora lo repito de nuevo [...] espero que a la mayor brevedad se me admita la renuncia...".

García del Río en nombre del protector acepta la dimisión y comunica a De las Heras que deberá viajar a Chancay. De las Heras reúne al cabildo el mismo día 28, deja por gobernador con todas sus facultades al deán y al cabildo. Lo era a la sazón don Francisco Xavier Echagüe, natural de Córdoba de Tucumán, que había ingresado al coro metropolitano como prebendado en 1787 , ascendiendo a canónigo en 1797, a dignidad de tesorero en 1809, de chantre en 1812 y de deán en 1814, el cual ejerció el gobierno de la arquidiócesis en virtud de esa delegación. ${ }^{10}$

De las Heras se despidió de San Martín por carta del 5 de setiembre de 1821:

He sentido no poder dar a usted un abrazo antes de mi partida, ratificarle mi constante y buena voluntad y darle con el afecto más ingenuo, las debidas gracias porque me ha aliviado de una carga superior a mis fuerzas, llenando mis deseos de acabar mis días sin ella, para dedicarme a pedir a Dios el perdón de mis pecados hasta mi muerte, que no debe estar distante, en la edad octogenaria en que me hallo. Quiero pedirle a usted en señal de nuestra recíproca amistad y es que me permita la satisfacción de aceptar de mis muebles una carroza y un coche que entregará a usted, a su regreso, mi secretario y juntamente un dosel de terciopelo y dos sillas; pueden servirle para los días de etiqueta, y una imagen de la Virgen de Belén, que ha sido mi devota.

Créame usted, amigo, que lo encomiendo a Dios diariamente para que le dé la paz al reino cuanto antes. Jamás olvidaré las expresiones de afecto y consideración con que me ha distinguido cuando nos hemos visto, y lo será en todas ocasiones, su más apasionado amigo y capellán que besa su mano. Lima, setiembre 5 de 1821. Bartolomé María de las Heras..11

La carta refleja el corazón bondadoso y el forjado temple del arzobispo. La asertividad con la que trata a San Martín revela también la gallardía del Libertador y lo doloroso que tuvo que ser para él no poder corresponder al prelado con la misma hidalguía. La memoria consignada del encuentro secreto deja entrever la buena voluntad de San Marín, condicionado por las arbitrariedades del momento. Todo apunta como culpable a Monteagudo, del cual el protector San Martín supo desentenderse en la crítica coyuntura de setiembre, en la que asomaba el ejército realista de Canterac con la posibilidad de retomar Lima y frustrar la gesta emancipadora.

10 Fallece el 17 de diciembre de 1830 en Lima, electo obispo de Puerto Rico.

11 Rubén Vargas Ugarte, El episcopado en los tiempos de la emancipación sudamericana (18091930). Buenos Aires, 1932, p. 121. 
De Lima el arzobispo renunciante se encaminó por tierra hacia el norte hasta llegar a la caleta de Chancay. Allí se embarcó en una fragata angloamericana en compañía de sus familiares, el citado Nicolás Tadeo Gómez y Valentín Zorzano. No fue por Panamá como solicitó el anciano prelado y había prometido el gobierno protectoral, sino que el 13 de noviembre la fragata zarpó hacia el sur, donde sufrió las embestidas del océano en el Cabo de Hornos, hacia Río de Janeiro.

Desde la capital brasileña, el arzobispo envió una carta a Lord Cochrane, cuyos marinos, sin conocimiento de San Martín, habían saqueado algunas iglesias del litoral. En la carta se muestra convencido de "estar sellada para siempre la independencia del país", y que así lo manifestará al gobierno y a la Santa Sede, y que haría "cuanto pudiese para vencer su obstinación, mantener la tranquilidad y secundar los votos de los habitantes de América que tanto apreciaba". ${ }^{2}$

El duro viaje, más si lo sufre un anciano casi octogenario, le costó 7,500 pesos hasta Lisboa; nueva promesa incumplida del gobierno protectoral. Por fin llega a Madrid en julio de 1822. Una vez recuperadas las fuerzas físicas y serenado su espíritu, se comunica con el nuncio Giustiniani y redacta un detallado informe que firma el 3 de diciembre de 1822 y que es un arsenal de datos sobre la situación del Perú. Interesan las referencias al alto clero, partidario de la emancipación y de un derecho canónico acomodado a aquellas tierras y, por lo tanto, elaborado allí. Interesa también la semblanza de las virtudes y los vicios de los peruanos, la relativa relajación de las órdenes religiosas, la evolución de los sucesos en la proclamación de la independencia, con la permanencia y expulsión del prelado. Hace una relación de clérigos episcopables, con tal lujo de detalles que, dada su edad, constituyen un alarde de memoria. Y ofrece soluciones: envío de algún delegado de la Santa Sede y nombramiento de obispos, con las cualidades que deben tener para aquellos momentos.

Murió el 27 de enero de 1823, a los 79 años, en el convento de Trinitarios Descalzos. ${ }^{13}$ Enseguida se tocó a sede vacante, se reunió el cabildo y eligió al propio Francisco Xavier Echagüe, deán y vicario capitular, para que continuara como tal gobernando el arzobispado, lo que hizo hasta su fallecimiento en 1831.

\section{La valiosa biblioteca donada al Seminario de Santo Toribio}

Evidentemente una personalidad tan destacada fue formando una biblioteca notable. Conocemos la inventariada en 1791 y la donada al Seminario Santo Toribio en 1816, que se conserva en el legajo 49 del archivo, donde se

12 William Bennet Stevenson, Memorias sobre las campañas de San Martín y Cochrane en el Perú. Madrid, 1919, pp. 166-168.

13 Así se recoge en la nota necrológica insertada al final del índice del Libro de bautismo n. 8 de la iglesia parroquial de Santa María de Carmona.

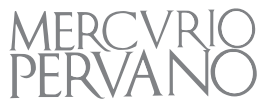


guardan también otros catálogos e inventarios de libros del seminario: los de Belisario A. Philipps (1939), de la Congregación Hijos de San José (19178), entre otros. Algunos títulos de la biblioteca del obispo De las Heras se conservan todavía, otros se han perdido; la mayoría son textos del siglo XVIII. ${ }^{14}$ El libro-inventario de diciembre de 1967, en 143 páginas, nos da cuenta de 3341 títulos, con el autor, la ciudad y el año de impresión. El último inventario, y el más completo, es un tomo de 465 hojas con la catalogación de los libros ingresados hasta marzo de 1996, que comprende la información de 17648 obras, con su fecha de ingreso, nombre del autor, título, lugar de impresión, año, procedencia. Desde esa fecha hasta la actualidad (octubre 1999) están anotados en dos cuadernillos en poder del bibliotecario de la Biblioteca de Teología. ${ }^{15}$

Se supone que el palacio arzobispal contaría con libros de consulta personal para su alimento espiritual y para el desempeño de su ministerio episcopal. Por el momento nos complace dar a conocer su donación al seminario, testimonio elocuente de su generosidad, así como instrumento valioso para conocer la mentalidad del donante. El libro, encuadernado en pergamino, lleva por título "Índice manual de los libros que donó a este Real Seminario de Santo Toribio el Excelentísimo e Ylustrísimo Señor Doctor Don Bartolomé María de las Heras, su especial Mecenas". Año de 1816. [26 hojas, hasta la 35 en blanco]. En el mismo se expresan los nombres de los autores por orden alfabético, y se indica el título de la obra, el número de tomos en que se contiene, el estante y la línea donde se halla:

Allapide, Cornelio, Comentario sobre la escritura. 9 tomos en folio.

Ambrosio, Santo, Obras varias. 2 tomos en folio.

Agustín, Santo, Obras varias. 10 tomos en 8 vols.

Aponte, Cayetano, Colección de resoluciones de la Congregación del Concilio Tridentino. 4 tomos en cuarto menor.

Aguirre, José, Compendio de los concilios de España. Un tomo en $8^{\circ}$.

Acebedo, Alfonso Comentario al derecho español. 6 tomos en 3 volúmenes de a folio.

- Consejos varios.

Alfaro, Francisco de,_Acerca del oficio del fiscal y sus privilegios.

Agustín de Virgen María, Privilegios de los órdenes religiosos.

Avicela, Gabriel, Privilegios regulares en la administración de la penitencia.

14 Hemos cotejado solo algunos títulos, pero es posible hacer una pesquisa más exhaustiva a partir de la Bibliografía de autores españoles del siglo XVIII (10 vols.), de Francisco Aguilar Piñal. Madrid, Consejo Superior de Investigaciones Científicas, 1981-2001.

15 Ver José Antonio Benito, "Archivo y biblioteca del Seminario de Santo Toribio de Lima". Revista Peruana de Historia Eclesiástica, 7, Cusco, 73-114. 
Antonelli, Carlos, Tratado de loco legali (2 t.). ${ }^{16}$

Avendaño, Diego de, Tesoro Índico (5 t.). ${ }^{17}$

Antonio Agustino, Epítome del derecho antiguo pontificio (2 t.).

Azpilcueta, Martín, Manual de confesores y penitentes.

Aydekin, Ricardo, Teología dogmática escolástica con varios apéndices curiosos. ${ }^{18}$

Antonio Gabriel, Teología moral (2 t.).

Alamin, Felipe, Sobre la felicidad natural y sobrenatural del hombre. ${ }^{19}$

Argüelles, Manuel, Disertación histórico-teológica sobre la antigüedad de los párrocos. ${ }^{20}$

Álvarez, José de, Epítome de la vida de los pontífices hasta Benedicto XIV (8 t.).

Azor, Juan, Instituciones morales (3 t.).

Alcedo, Antonio, Diccionario geográfico la América (5 t.). ${ }^{21}$

Anónima, Apéndice a la educación popular (3t.).

Antonio, Nicolás, Biblioteca española antigua (4 t.).

Andrés, Juan, Origen y estado actual de la literatura (2 t.).

Apología de los jesuitas.

Ayala, Juan de, El pintor cristiano (2 t.).

Arte de lengua quechua.

Acosta, José de, Modo de promulgar el Evangelio entre los bárbaros.

Alcuino, Monsieur, Colección de homilias (3 t.).

Castejón, Egidio, Alfabeto jurídico canónico civil teórico-práctico, moral y político (2 t.).

16 Se trata de la obra del cardenal Giovanni Carlo Antonelli, Tractatus de Loco Legali in Tres Libros Distributus, In Quibus Nedum Utriusque Iuris Controversiae Difficiliores, \& In Foro Frequentiores, Quoad Locum Singulariter Tractantur, \& Resoluuntur. Opus Omnibus tam in Scholis, Quam in Palatiis Versantibus, Theoricis, \& Practicis Apprime Utile, \& Necessarium. Argumentis, Summariis, \& Diversis Indicibus, \& Praesertim Materiarum Decoratum. Se publicó en Venecia, en casa de Nicolaum Pezzana, en 1687, con ediciones sucesivas en los años siguientes.

17 El jesuita Diego de Avendaño vino al Perú muy joven, donde murió luego de casi medio siglo de estancia en este país. Publicó su Thesaurus Indicus en Amberes, en 1668-1686.

18 Richard ARCHDEKIN (1618-1693), Theologiae tripartitae tomus primus: complectens controversias heterodoxas ac scholasticas... Amberes, 1696.

19 Se trata de la obra del religioso capuchino Félix de Alamin, La felicidad o bienaventuranza natural y sobrenatural del hombre... Madrid, Imprenta de Roman, 1723.

20 Juan Manuel Argüelles, Disertación histórico-teológica sobre la antigüedad de los párrocos: ilustrada en varios discursos, Madrid, 1778.

21 Diccionario geográfico histórico de las Indias occidentales o América, es a saber, de los Reynos del Perú, Nueva España, Tierra Firme, Chile, y Nuevo Reyno de Granada: con la descripción de sus provincias, naciones, ciudades... y noticia de los sucesos más notables de varios lugares. Madrid, Imprenta de Benito Cano, 1786-1789. 
Alejandro, Natal. Teología moral, tomo 30.

- Historia eclesiástica (17 t.)

- Exposición de Evangelios (2 t.).

- Exposición de las cartas de S. Pablo y las demás canónicas (3 t.).

[B]

Biblia Sacra con notas de Duhamel y Batablo (4 t.).

Becano, Marín, Analogía del Viejo y Nuevo Testamento.

Bernardo, Santo, Obras varias.

Benedicto XIV, Obras varias (12 t.).

- Su Bulario (4 t.).

Bielfelt, Instituciones políticas (2 t.).

Berardi, Ilustración a la colección de Graciano (3 t.).

Id. Comentarios al derecho eclesiástico (3 t.).

Baubeuf, Andrés, Uso y abuso del derecho.

Ballo, Gomecio, Práctica eclesiástica. ${ }^{22}$

Barboja, Agustín, Colectáneas sobre el derecho pontificio. 6 t en folio.

Id, Acerca del oficio de canónigos y ministros de las catedrales, 1 tomo en latín

Id, Acerca del oficio del párroco (1 t.).

Id, Colectáneas de doctores que deciden algunos puntos con arreglo al Concilio Tridentino, 1 tomo de a folio.

Id, Compendio de las decisiones apostólicas que están fuera del cuerpo del derecho.

Id, Tratados varios.

Id, Sobre los votos decisivos y conflictivos del derecho canónico (2 t.).

Berti, Lorenzo, Teología escolástica.

Besombes, Jacobo, Teología moral. 2 t. en 1 vol.

Blandiniere, Abad de, Colección de conferencias eclesiásticas tenidas en Angers (24 t.).

Burio, Guillermo, Breve noticia de los sumos pontífices.

Bonacina, Martín de, Todas sus obras (2 t.).

Bona, Cardenal Juan de, Todas sus obras.

Baronio, César, Anales eclesiásticos (12 t.).

Id, Martirologio romano.

22 Se trata de la obra de Gómez BAyo, Práctica eclesiástica y secular de todas las causas. Madrid, 1628 . 
Bobio, Abraham, Continuación de los anales eclesiásticos de Baronio (2 t.).

Id, Compendio de los anales eclesiásticos de Baronio (2 t.).

Berti, Lorenzo, Historia eclesiástica (4 t.).

[Bv]

Barruel, Abate, Historia de la persecución del clero de Francia.

Barcia, Andrés, Colección de historias de las Indias (3 t.).

Bare, Guillermo de, Bibliografía instructiva (9 t.).

Borzio, Antonio de, Monumentos de Roma (2 t.).

Bacallar, Vicente de, Comentarios de la guerra de España (2 t.).

Bonnani, Felipe, Catálogo de los órdenes religiosos (4 t.).

Becatini, Francisco, Vida de Carlos III (2 t.).

Buffon, Conde de, Historia natural del hombre (2 t.).

Bellegarde, Abab de, Arte de conocer a los hombres.

Berni, Juan Baptista, Filosofía (4 t.).

Bocanegra, Alejandro de, Sermones (2 t.).

Borof, Luis de, Sermones.

Brisson, Monsieur Curso de Física (4 t.).

Id, Diccionario de Física, 9 t. y un suplemento.

Biblioteca francesa. Viaje de la letra.

Bulario romano (28 t.).

Nota:

Aunque la Biblia esté expuesta por varios autores que se encuentran allí, me remito por ahora a las iniciales de los hombres de los autores que la exponen.

Brandin, Abel Victorino, Influencia del clima sobre el hombre.

[C]

Calmete Agustín de, Comentarios de la Escritura Sagrada (8 t.).

- Diccionario geográfico de la Sagrada Escritura (2 t.).

Cipriano, Santo, Obras varias.

Crisóstomo, Santo, Obras varias (13 t.).

Colección de constituciones pontificias en favor de los crucíferos.

En favor de los padres de san Juan de Dios (2 t.).

Castro, Francisco de, Discurso para las leyes (3 t.).

Colón, José, Instrucción para escribanos y abogados (2t.). 
Colección de providencias para el gobierno de los oficiales de temporalidades.

Carlebalio, Del foro competente (2 t.). ${ }^{23}$

Covarrubias, José de, Recursos de fuerza.

Cañada, Conde de, Recursos de fuerza.

Id, Juicio imparcial.

Conferencias de Angers (24 t.).

Capisio, Decisiones sobre el derecho civil (2 t.).

- Consultas del derecho civil (2 t.)

Colección de decisiones sobre el derecho según la doctrina de varios jurisconsultos, obra anónima.

Castillo, Juan de, Controversias del derecho (8 t.).

Id, Decisiones de la rota romana.

Cabalario, Domingo, Institución del derecho. 6 vol. en 3 tomos.

Clericato, Juan, Decisiones sacramentales (3 t.).

Id, Decisiones forenses (3 t.).

Campomanes, D. Pedro, Tratado de la amortización

Cuerpo del Derecho (2 t.).

Cortiada, Miguel, Decisiones del Senado de Cataluña (4 t.).

Caponi, Julio, Disertaciones forenses (3 v.).

Castejón, Exidio de, Alfabeto jurídico (2 t.).

Castro, Antonio de, Alegatos canónicos con sus decisiones.

Castro, José de, Misceláneas de disertaciones canónicas, civiles y criminales.

Causas eclesiásticas (9 t.).

Cueva, Alonso de, Concordia de la discordia sobre un punto de la inmunidad eclesiástica.

Cornelio, Pedro, Historia eclesiástica.

Castel, Antonio de, Comentarios a los cuatro libros de Pedro Lombardo (5 t.).

Cano, Melchor, Sus obras (2 t.).

Cabades, Agustín de, Instituciones teológicas (4 t.).

Corella, Jaime de, Conferencias morales (6 t.).

Id, Práctica del confesonario.

Castropalao, Fernando de, Teología moral (3 t.).

Concina, Daniel del, Epístolas a Noecio. Apologías y papeles curiosos. 8 cuadernos.

23 Tomás Carlevalio (1576-1645), Disputationum Juris Variarum De Judiciis; ad interpretationem Regiarum legum Regni... (varias ediciones). 
Id, Disciplina monástica (2 t.).

Id, De la usura del contrato trino y acerca de la opinión probable (2 t.).

Corzza, Lorenzo, Cuestiones sobre el solicitante in confesione.

Cabasucio, Juan, Noticias eclesiásticas.

Castel, Gerardo de, Controversias histórico-eclesiásticas.

Croisset, Juan, Año cristiano (13 t.).

Castillo, Diego del, Comentario literal y moral del cap. 28 de Éxodo.

Columbo, Felipe, Vida del P. Urraca.

Cresier, Monsieur, Continuación de la historia de Rollín.

Corbalán, Juan de, Descripción del obispado de Osma (3 t.).

Cárdenas, Gabriel de, Ensayo cronológico de la historia de la Florida.

Constituciones de la Universidad de Salamanca.

Constituciones de la Universidad de Lima.

Condillac, Abate de, Ensayo sobre el origen de los conocimientos humanos (3 t.).

Casties, Abad de, Historia de los tres siglos de la literatura francesa (4 t.).

Calzada, Bernardo de, versión al castellano de la Historia de Tigosai (2 t.).

Cervantes, Miguel de, Historia de don Quijote (4 t.).

Caulin, Antonio de, Historia de Cumana y Guayana.

Colección de varios papeles que dio a luz el Sr. Moxoo con relación a los sucesos de Buenos Ayres en el ingreso del inglés (2 t.).

Colección de los mejores diarios que se han publicado en Europa.

Colección de Mercurios Peruanos dados a luz por la Sociedad Académica (8 t.).

Cicerón, Marco Tulio, Sus obras (9 t.).

Caraccio, Marqués de, Posesión de sí mismo.

Id., Grandeza del alma

Id., Religión del hombre de bien.

Id., Pintura de la muerte.

Id., Caracteres de la amistad.

Id., El cristianismo de estos tiempos (2 t.).

Id., El universo nigmático.

Id., La despedida de Mariscala.

Id., Cartas de Clemente XIV (9 t.).

Id., Vida de Clemente XIV.

Id., El clamor de la verdad. 
$[\mathrm{Cv}]$

Id., Viajes de la razón (2 t.).

Id., La verdadera alegría.

Constantini, Cartas críticas sobre varios asuntos (12 t.).

Cajón de sastre aumentado por Cubillas (6 t.).

Casiodoro, Marco Aurelio, Todas sus obras (2 t.).

Calepino, Ambrosio, Diccionario de 8 lenguas.

Clemente, Abad de, Sermones varios (8 t.).

Castro, Ignacio de, Disertaciones apologéticas de la Inmaculada Concepción.

Colonia, Tratado de la religión cristiana (2 t.).

Cliquet, Faustino, Su teología moral ilustrada por Belza (3 t.).

Colección de los soliloquios de S. Agustín.

Colección selecta de algunas oraciones de Cicerón (2 t.).

Curia filípica, por Juan Bolaños.

[D]

Duhamel, Juan, Anotaciones de la Biblia (2 t.).

Diccionario histórico y geográfico de la Biblia, por don José Ginaceo $\left(4 \mathrm{t}\right.$.). ${ }^{24}$

Diccionario de los concilios con un apéndice de los herejes (2 t.).

Diccionario de la América por D. Antonio Salcedo (5 t.). ${ }^{25}$

Diccionario de los cultos religiosos por un anónimo (3 t.).

Diccionario histórico de los varones ilustres, escrito por una sociedad literaria (8 t.).

Diccionario portátil de varones ilustres (3 t.).

Diccionario de Morell, solo 6 t. hasta la letra L.

Diccionario de Ferreros (4 t.).

Diccionario de Ferreros (8 t.).

Diccionario 8 lenguas por Calepino.

Diccionario de la lengua castellana escrito por la Academia Española (6 t.).

Diccionario de Rubiños (2 t.).

Diccionario Sobrino (3 t.).

Diccionario de Sejournan (7 t.).

24 Parece referirse al Diccionario histórico cronológico, geográfico y universal de la santa Biblia, de José Armesto y Goyanes, hecho en Madrid, Imprenta de Blas Román, 1789.

25 Se refiere a la obra de Antonio de Alcedo, ya mencionada. 
Diccionario eclesiástico (véase la letra V).

Diccionario universal de Física por Mons. Brison.

Diccionario de uno y otro derecho (véase la letra V).

Diccionario jurídico por Castejón (véase la letra A).

Diccionario numismático parra la inteligencia de las medallas antiguas por don Tomás de Guseme (6 t.).

Domínguez, José, Adiciones a la curia filípica (4 t.).

Deboti, Juan, Instituciones canónicas (3 t.).

Dávalos, Diccionario de los jueces eclesiásticos.

Delbeme, Tomás, Del oficio de la Inquisición.

Defensa de la libertad eclesiástica.

[D]

Danés, Luis de, Instituciones de la doctrina cristiana con una breve noticia de los tiempos (3 t.).

Ducreus, Abate. Historia eclesiástica (12 t.).

De Campos, Esteban, Acerca de la herejía de Jansenio.

Diana, Antonio, Resoluciones morales.

Ducange, Carlos, Glosa de los escritores latinos de la edad infima y media (6 t.).

Duchesne, Compendio de la historia de España.

[E]

Efrén, Santo, Obras varias. 3 t. del griego al latín. La misma obra del texto siríaco al latín (3 t.).

Epístolas selectas, de san Jerónimo.

Elizondo, Francisco, Práctica universal forense (6 t.).

Engel, Luis de, Principios del derecho canónico.

Epereyo, Alejandro, Decisiones del fuero eclesiástico (2 t.).

Ercilla, Alonso de, La Araucana [2 r].

El filósofo incógnito o la mujer feliz (3 t.).

Exequias de la princesa María Antonia de Borbón. Folleto.

Eguiga, (Félix de).

Esperanza cristiana por el Marqués de la Regalía.

[F]

Friderico, Francisco, Jurisprudencia pública. 
Frazo, Pedro, Tratado al Patronato Real de Indias (2 t.).

Fleuri, Abad, Instituciones del derecho eclesiástico (2 t.).

Farinaleo, Próspero, Obras varias (11 t.).

Fargena, Francisco, Comentarios a las leyes de patronato.

Fermín, Felipe, Tratado de capellanías.

Febronio, Justino, Tratado de la potestad del pontífice romano (4 t.).

Fermosino, Nicolás, Sobre el derecho civil y canónico (12 t.).

Fuerzas eclesiásticas (3 t.).

Fleuri, Claudio Abad, Costumbres de los israelitas.

- Costumbres de los cristianos.

Flores, Enrique, Teatro geográfico de las iglesias de España (32 t.).

Fama póstuma del Sr. La Reguera.

Flecer, espíritu de, Historia del cardenal Jiménez. ${ }^{26}$

- Sermones varios (6 t.).

Fleury, Abate, Catecismo histórico de la doctrina cristiana.

Fenelón, D. Francisco de, Aventuras de Telémaco.

- Diálogo de las muertes.

-Diálogo de los muertos traducido al castellano (2 t.).

Feijoo, Benito, Teatro crítico (8 t.).

-Cartas críticas (6 t.).

Feliu, Ramón, Uso de la lengua vulgar en el estudio de las ciencias.

\section{[G]}

Ginases, José, Diccionario histórico y geográfico de la Biblia (4t.). ${ }^{27}$

Jerónimo, Santo, Comentarios sobre la Escritura Sagrada con el resto de sus obras (11 t.).

Gregorio, Santo Papa, Comentarios morales con el resto de sus obras (4 t.).

Gregorio Neocesariente, Colección de sus obras con las de san Macario y san Basilio.

Galomar, Juan, Annotaciones al concilio de Trento.

Gomecio, Antonio, Revoluciones sobre el derecho civil.

- Comentarios a las leyes del foro.

González, Manuel, Comentarios a los cinco libros de las decretales de Gregorio

26 Se refiere a Espíritu Fléchier (1632-1710), uno de los más célebres oradores sagrados de Francia, muy reconocido por sus sermones.

27 Ver la nota 20. 
$I X$.

Gutiérrez, Juan, Cuestiones canónicas.

- Acerca de la tutela y de la obligación de los tutores de menor.

- Cuestiones prácticas sobre la ley de España según el orden de la nueva colección (3 t.).

- Tratado de Gavelar (2 t.).

- Repetición y alegaciones varias.

- Consejos acerca del derecho.

- Cuestiones prácticas en materias criminales.

- Cuestiones acerca del matrimonio con respecto al foro interno y externo.

- Resoluciones acerca del juramento.

González, Jerónimo, Comentario de la regla octava cancelaria acerca de la observación de mejes y alternativa de obispos.

Graña Nieto, Antonio, Comentarios de los libros de los decretales.

Gotti, Luis, Apología de la Yglesia, obra escrita contra Picenino.

Gilbet, P., Nueva traducción del griego al francés de las antigüedades judaicas escritas por Josefo (4 t.).

Gabanto, Bartolomé, Comentarios a las rúbricas del misal y breviarios romanos con las adiciones de Morati (4 t.).

García, Vicente, Teatro español (16 t.).

Gil, Francisco, Disertación médica sobre el modo de preservar de las viruelas.

Guía de viajantes de Lisboa para algunas cortes.

González, Francisco, Instrucción para seminarios conciliares.

Guzeme, Tomás, Diccionario numismático (6 t.).

Gouget, Abate, Biblioteca francesa (18 t.).

Gallo, Nicolás, Sermones varios.

[H]

Hugo, Cardenal, Comentarios de la Sagrada Escritura (8 t.).

Harduino, Juan, Colección de concilios (12 t.).

Heinecio, Juan, Obras varias (8 t.)

Habert, Luis, Teología dogmática y moral (7 t.).

Henno, Francisco, Teología escolástica dogmática y moral (6 t.).

Hurtado, Francisco, Teología moral (4 t.)

Helena, Gerónimo, Compendio de la teología moral de los salmanticenses.

Honorato, P., Reparos varios en las reglas y uso de la crítica en la historia eclesiástica (3 t.). 
[I]

Isidoro, Santo hispalense, Tratados varios (2 t.).

Jeseas, Gonzalo de, Primera parte de la historia de los pontífices romanos desde el tiempo de Jesucristo hasta el año de 1652.

Isla, Francisco de, Versión al castellano del compendio de la historia de España escrita en francés por Duchesne (2 t.).

- Cartas de Juan de la Encina.

- Sus cartas familiares.

Iriarte, Tomás de, El nuevo Robinson vertido del francés al castellano (2 t.).

[L]

Labey, Felipe, Colección de los concilios (29 t.).

Lorenzana, Francisco, Colección de concilios de México (2 t.).

Lancelote, Juan, Instituciones canónicas o del derecho canónico.

Leurenio, Pedro, Foro eclesiástico acomodado a los libros de las decretales de Gregorio con varias cuestiones y respuestas de profesores de ambos derechos.

- Acerca del foro beneficial con cuestiones y respuestas canónicas relativas a esta materia (3 t.).

Leznia, Juan, Suma de cuestiones acerca de los casos de conciencia relativos a los regulares de uno y otro sexo (4t.).

Lainense, Jacinto Donato, Práctica de la resolución de algunas cuestiones de regulares (obra trunca).

Larrea, Juan, Decisiones del Senado de Granada.

- De alegatos de fiscales.

Luca, Juan de, Decisiones civiles y canónicas (21 t.).

Lupo, Cristiano, Privilegios de la silla apostólica en casos de apelación (13t.).

Ledesma, Pedro de, Suma moral (2 t.).

Leiman, Pablo de, Compendio de la teología moral (2 t.).

Lebrún, Pedro de, Historia de las supersticiones que ha habido en algunos pueblos.

Largo, Domingo, Tratado sobre el matrimonio.

Lara, Ildefonso, Todas sus obras.

Lecio, Leonardo, Tratado de las virtudes cardinales.

Lacioi, Claudio, Teología moral (2 t.).

Labillano, Fermín de, versión al castellano de los entretenimientos de Focio. 
[L]

Lobo, Gerardo, Sus obras poéticas.

Leruela, Miguel de, Restauración de la abundancia de España.

Lampilla, Abate, Ensayo de lo histórico-apologético de la literatura española.

López, Antonio, Principio del orden de la naturaleza.

Lafondi, Monsieur, Versión al francés de la física experimental escrita por Pedro Marchembroch en otro idioma (3 t.).

Lanuza, Vicente, Tratados evangélicos (2 t.).

Levade, Monsieur, Sermones varios.

Lafitau, Monsieur, Sermones varios (2 t.).

La alma cristiana formada sobre las máximas del Evangelio.

Larraga, P. Prontuario moral.

[M]

Maritini, Martín, Reglas para interpretar la Escritura Sagrada.

Martínez, Juan, Explicación de la doctrina cristiana.

Masillon, Sermones varios con otros pequeños tratados (13 t.). ${ }^{28}$

Muratori, Luis Antonio, Tratado de la devoción arreglada.

- Filosofía moral.

- Fuerza de la humana fantasía.

- Reflexión sobre el buen gusto a las ciencias.

Montalvo, Francisco, Vida de santo Toribio.

Mayans, Gregorio, Colección de cartas morales, civiles y militares (9 t.).

Moreau, José de, Tratado histórico de la vacuna.

Moreri, Diccionario histórico (trunca) $\left(6\right.$ t.). ${ }^{29}$

Mayr, Antonio, Filosofía peripatética. ${ }^{30}$

Manrique, Jorge, Coplas glosadas por Guzmán.

Musa mexicana (trunco).

28 Juan Bautista Massillon, presbítero de la Congregación del Oratorio y obispo de Clermont (Francia).

29 Luis MORERI, historiador francés, autor de un gran diccionario histórico inacabado (1671). La obra fue añadiendo ampliaciones y suplementos hasta tener cinco volúmenes en 1713. Desde la edición de 1725 constaba de seis volúmenes, y fue la octava edición la que se tradujo al castellano en 1753. Llegó a tener ocho tomos en diez volúmenes.

30 Antonio Mayr (1673-1749), jesuita, autor de una Philosophia peripatetica antiquorum principiis et recientiorum experimentiis confirmata, publicada en Venecia, Imprenta de Nicolás Pezzana, 1755.

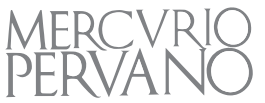


Mercurio Peruano (8 t.).

Murillo, Pedro, Curso del derecho canónico.

Nota

En esta letra $\mathrm{M}$ se ha invertido el orden de los autores según sus materias por haber sobrevenido después otra lista con la misma inicial.

Maldonado, Juan, Comentario de los cuatro evangelistas.

Menochio, Jacobo, Respuestas varias sobre el derecho civil y canónico (13 t.).

- De la retención y recuperación de posesión.

- De la jurisdicción eclesiástica y secular.

Mateu, Tratado de materias criminales.

$[\mathrm{Mv}]$

Memorial presentado al rey sobre diferentes cartas del obispo de Cuenca.

Molina, Acerca de la justicia y del derecho (5 t.).

Mosta, Francisco, Tratado de causas pías (2 t.).

[N]

Neker, Administración de las finanzas a la Francia (3 t.).

Noel, Francisco, Compendio de la teología de Suárez (2 t.).

Nicole, Abate, Tratados varios (8 t.).

Nota

Los demás libros sobre moral de este autor se mandaron a entregar por S.E.I. al R. P. Orihuela como consta en su recibo, y aunque el precepto se extendió a la entrega de los demás tomos de nuestro autor, sin embargo he reservado lo arriba referido.

Núñez, Alonso, Tratado histórico-político de Madrid.

Nepote, Cornelio, Historia selecta de algunos varones ilustres.

Nipho, Francisco de, Colección de varios discursos elocuentes sobre las acciones de algunos personajes.

Neuville, Carlos de, Sermones varios (4 t.).

Nicole, Abate, Geografía moderna (8 t.).

[O]

Orígenes (P. de la Iglesia), Comentario de los Evangelios (2 t.). 
Olavide, Pablo, Versión parafrástica de los salmos de David (2 t.). ${ }^{31}$

Olmedo, Elementos del derecho público (2 t.).

Olea, Alfonso, Tratado de acciones del derecho.

Ortiz, Francisco, Curia eclesiástica para secretarios.

Oliva, Feliciano, Tratado del fuero eclesiástico.

Orsi, Agustín de, Historia eclesiástica (26 t.).

Osta, Luis, Su carta pastoral.

Ovidio, Publio, Sus obras (4 t.).

Oviedo, Antonio de, Vida de santa Rosa de Lima.

Oráculo de los nuevos filósofos o Voltaire refutado por un anónimo (2 t.).

Ochagavia, Antonio de, Manual de la misa rezada.

Oviedo, Rodrigo de, Colección de las oraciones de Cicerón (2 t.).

\section{[P]}

Paschal, Monsieur, Pensamientos sobre la religión (2 t.).

Petavio, Dionisio, Teología dogmática (6 t.) (0 tr.).

- Doctrina de los tiempos (3 t.).

- Racionario de los tiempos con adición de los opúsculos de Jacobo Usebio.

Potesta, Félix, Examen eclesiástico. 3 t. en un vol.

Pérez, Diccionario portátil de los concilios (2 t.).

Parra, Colección de bulas en favor de los PP de San Juan de Dios (2 t.).

Pisto Aletino, Sobre el Papa y sus facultades (2 t.).

Parlador, Obras jurídicas.

Parras, Gobierno de regulares de la América (2 t.).

Panormitano, Nicolás Tudesco, Exposición de los libros de las decretales de Gregorio (4 t.).

Pérez, Francisco, Defensa canónica de la potestad de los obispos.

Pontaz, Monsieur, Diccionario de casos de conciencia con notas de Colet. (2 t.). ${ }^{32}$

Pareja, Gabriel, Práctica de hacer instrumentos en derecho.

31 Pablo de Olavide (1725-1803), Salterio español o versión parafrástica de los salmos de David, de los cánticos de Moisés, de otros cánticos y de algunas oraciones de la Iglesia en verso castellano, a fin de que se puedan cantar: para uso de los que no saben latín. Lima, Imprenta de la Real Casa de los Niños Expósitos, 1803. Este volumen, al igual que otros muchos de la colección del obispo, se conservan hasta hoy en la biblioteca del seminario.

32 Jean Pontas (1638-1728), presbítero francés, cuyo diccionario se publicó por primera vez en 1715, luego se tradujo al latín. Collet publicó un compendio en 1764 y 1770, también en dos volúmenes. 
Pitonio, Francisco de, Controversias acerca del patronato eclesiástico y otras materias de derecho $(2 \mathrm{t}$.).

- Decisiones eclesiásticas con la colección de decretos de la Dataria Romana (4 t.).

- Papeles relativos a los regulares y monasterios (2 t.).

Patuzi, Vicente, Teología moral (7 t.).

Pérez, Nicolás, Versión al castellano del catecismo romano (2 t.).

Polidoro, Tratado de la invención de las cosas.

Pagi, Antonio, Crítica a los Annales de Baronio (4 t.).

$[\mathrm{Pv}]$

Persecución de los jesuitas al obispo Cárdenas (2 t.).

Pons, Antonio de, Viaje de España.

Panduro, Lorenzo, El hombre físico (2 t.).

Popé, Monsieur, Ensayos sobre el hombre. ${ }^{33}$

Piquer, Andrés, Filosofía moral.

Pluché, Abad, Espectáculo de la naturaleza (4 t.).

Palafox, Juan de, Sus obras (8 t.).

Vida interior.

Predicador instruido (6 t.).

$[R]$

Rosi, Bernardo, Aparato bíblico.

Ruperto, Abad, Comentarios de la Biblia Sagrada (3 t.).

- Opúsculos varios

Ricard, Carlos, Análisis de los concilios (11 t.).

Recopilación de las leyes de Indias (3 t.).

Reglamento del comercio de España con las Indias.

Riccio, Luis, Práctica del foro eclesiástico (2 t.).

- Decisiones de la curia arzobispal de Nápoles.

Ruprecher, Teodoro. Notas históricas a todo el derecho canónico.

Reifenstuel, Anacleto, Cuestiones sobre el derecho canónico (6 t.).

Reconco, José, Justa defensa de los prelados regulares contra el padre Asofrín.

33 Debe referirse al famoso poema de Alexander Pope, Ensayo sobre el hombre, publicado por primera vez en 1733-1734. José Joaquín Olmedo publicó una traducción al castellano en Lima, en 1823, aunque no pudo ser esa la edición que formaba parte de la biblioteca, cuyo inventario tuvo lugar en 1816. 
Ripalda, Juan de, Breve exposición del Maestro de las Sentencias.

Reinaldo, Orodico, Continuación de los anales de Baronio (10 t.).

- Epítome de los anales eclesiásticos (2 t.).

Río, Pedro del, Compendio metódico del cómputo eclesiástico, antiguo y moderno.

Rapin, Monsieur, Opúsculos varios (3 t.).

Rico, Juan de, Descripción de las exequias de Carlos II, folleto.

Regnaut, Monsieur, Curso físico (5 t.).

Rosel, Francisco de, Felicidades de España.

Ricciolo, Juan Baptista. Tratado de prosodia.

Robert, Geografía universal.

Rollin, M., Tratado de estudios (5 t.).

- Historia antigua (13 t.).

- Historia de las artes y ciencias (3 t.).

Rubiños, Alonso de, Colección del diccionario de Nebrija (2 t.).

[Rv]

Richelet, Pedro de, Diccionario portátil de la lengua francesa (3 t.).

Racine, Luis, Poema de la religión.

Roa, Tratado de algunas cosas singulares.

[S]

Sausi, Comentarios de las Escrituras Sagradas (32 t.).

Sabatier, Pedro, versión itálica antigua y nueva de la Biblia Sagrada con muchas notas curiosas (6 t.).

Scran, Domingo, Análisis de las obras de los SSPP (8 t.).

Sinodales de esta ciudad.

Sinodales de la Concepción de Chile.

Solórzano, Política indiana (3 t.).

- Recopilación de los diversos tratados y papeles en derecho.

- Emblemas varios.

Surdo, Pedro, Sobre el derecho civil (4 t.).

- Decisiones varias.

- Tratado de alimentis.

Salgado, Francisco, Laberinto de acreedores (2 t.).

- Decisiones de la rota romana.

- Tratado de la protección real a los que apelan de los tribunales.

- Tratado de las súplicas al Papa por bulas ofensivas a la regalía del soberano y del reino. 
Spiritu Santo, Antonio de, Consultas varias teológicas y jurídicas.

Soto, Domingo, Comentario del libro cuarto de Pedro Lombardo (2 t.).

Spondano, Enrique, Continuación de los anales eclesiásticos de Baronio (21 t.).

- Epítome de los anales eclesiásticos escritos por Baronio (2 t.).

- Anales del Antiguo y Nuevo Testamento.

Saliano, Jacobo, Anales eclesiásticos (6 t.).

- Compendio de la obra de Baronio (2 t.).

Sócrates y Sosomeno, Historia eclesiástica con texto griego y latino.

Sumario de la vida de Martín de Porras.

Sumario de la vida del Ve[nerable]. Messias [Juan Macías].

[S]

Suárez, José de, Defensa de la historia literaria de España.

Solís, Antonio de, Historia de la conquista de México (2 t.).

Sandoval, Prudencio de, Historia de Carlos V. (2 t.).

Sagé, M., Aventuras de Gil Blas (7 t.).

Silva, Francisco de, Década epistolar sobre el estado de las letras en Francia.

Sempere

Sanaubin, Tratado histórico y crítico de la opinión (7t.).

Sarmiento, Marín, Demostración crítica del teatro de Feijoo (2 t.).

Sejounam, M., Diccionario de la lengua francesa (2 t.).

Sobrino, M., Diccionario de la lengua francesa aumentada por Cormon (3 t.).

Sales, Santo Francisco de, Cartas espirituales (2 t.).

- Práctica del amor de Dios.

- Sermones (2 t.).

- Entretenimientos espirituales.

- El estandarte de la cruz.

- Vida devota.

San Real, Abad de, Obras varias (6 t.).

Sacle, M. Sermones varios.

Sermón de Nuestra Señora de Covadonga, estante 11, en el que se hallan otros sermones, como el del Sr. Masillon Neuville y otros.

[T]

Torniello, Agustín, Anales sagrados desde el principio del mundo hasta su... (2 t.). 
Tertuliano, Quinto Septilio, Apología de la religión cristiana.

Téllez, Manuel, Comentario del concilio iliberitano.

Tomasino, Luis, Disciplina antigua y nueva de la Iglesia (3 t.).

- Teología dogmática (2 t.).

Tejada, Juan, Tratado del proceso criminal de clérigos y legos.

Tourneli, Honorato, Curso de teología escolástica y dogmática (8 t.).

Tomás de Aquino, Suma de sus obras por Cayetano (12 t.).

Tamburiño, Tomás, Teología moral (5 t.).

Tamayo, Juan de, Martirologio español (6 t.).

Torquemada, Juan de, Monarquía indiana (2 t.).

Tomas, M., Sus obras (3 t.).

Torres, Diego de, Sus obras (14 t.).

Templo del honor y la virtud.

Tratado del estilo sublime.

Theses médicas.

Terreros, Esteban de, Diccionario de la lengua castellana.

Teresa de Jesús, Sus obras (4 t.).

Tomás de Jesús, Tratado de los sufrimientos de Jesucristo (2 t.).

[V]

Vatablo, Francisco, Anotaciones a la Biblia (2 t.).

Villanueva, Joaquín, Sobre la lectura de la Sagrada Escritura.

Valencia, Jacobo, Comentarios de los salmos de David (2 t.).

Vicat, Felipe, Vocabulario de ambos derechos (3 t.).

Velasco, Tratado de los privilegios de los pobres.

Vicensia, F. Gabriel, Privilegio de los regulares en la administración del sacramento de la penitencia.

Viritigoiti, Diego, Resoluciones varias en ambos derechos.

-Tratado de las competencias entre la curia eclesiástica y secular

Vela, José de, Disertaciones sobre el derecho civil.

Villalobos, Pedro de, Colección de papeles relativos a la inmunidad eclesiástica.

Villarroel, Gaspar, Gobierno eclesiástico y pontificio (2 t.).

Viña, Domingo, Curso teológico (2 t.).

- Colección de las proposiciones condenadas.

Viritigoiti, Fuero de conciencia.

Ubigan, Tribunal de confesores y ordenados. 
Valero, Carta pastoral.

Usettio, Jacobo,_Anales del antiguo y nuevo testamento (2 t.).

Vázquez, Agustín, Ilustración apologética al misal y breviario cisterciense.

Vida de san Juan Nepomuceno

Vida de santa Rosa de Lima

Vida del P. Urraca

Vida del V. Mesias

Vida del V. Porras

Vida de san Fernando

Vida de santo Toribio Arzobispo de Lima

Vega, Garcilaso, Historia del Perú (2 t.).

- Historia de la Florida

\section{[Vv]}

Ulloa, Antonio, Noticias americanas.

Valladares, Antonio, Semanario erudito (30 t.).

Vega, Félix de, Colección de sus obras (20 t.).

Unanue, Hipólito, Observaciones del clima de Lima.

Vives, Luis, Sus obras.

\section{[X]}

Ximénez, Francisco, Versión parafrástica de las epístolas de san Pablo.

Xamaso, Juan Baptista, Conocimientos de las 14 aves de jaula.

[Z]

Zaquías, Pablo, Cuestiones médico-legales (3 t.). 


\section{Bibliografía:}

Bruno, C. de, “El protector del Perú, General José de San Martín, y la relación del Arzobispo de Lima, Bartolomé María de las Heras", en Actas del I Congreso Internacional Sanmartiniano, vol. VI, Buenos Aires, 1978.

Castañeda Delgado, P. “La hierarchie ecclesiastique dans l'Amerique des lumieres", en L'Amerique Espagnole a l'époque des lumieres, París, Centre National de la Recherche Scientifique, 1987, pp. 79-101.

_., “Las convicciones religiosas de José de San Martín”, en L. Navarro García (ed.), José de San Martín y su tiempo, Sevilla, Universidad, 1999, pp. 133-155.

Fernández García, Enrique, Perú cristiano. Lima, Pontificia Universidad Católica del Perú, 2000.

García-Abásolo, Antonio, Itinerario chileno y peruano de Nicolás Tadeo Gómez (17551839). De sobrecargo del navío Príncipe Carlos a mayordomo del último arzobispo español de Lima (1783-1822). Córdoba, Editorial de la Universidad de Córdoba, 2015.

Leturia, Pedro, Relaciones entre la Santa Sede e Hispanoamérica (1493-1835) vol. II, Época de Bolívar, volumen revisado por el padre Carmelo Sáenz de Santa María. Universidad Gregoriana-Sociedad Bolivariana de Caracas, Roma-Caracas, 1960.

Méndez Bejarano, Mario, Diccionario de escritores, maestros y oradores naturales de Sevilla y su actual provincia. Sevilla, Libros Padilla, 1989.

Mira Caballos, Esteban, "Sobre el carmonense Bartolomé de las Heras, arzobispo de Lima (1743-1823)", Revista Carmona y su Virgen de Gracia. Carmona, setiembre del 2012, http://estebanmira.weebly.com/uploads/7/9/5/0/7950617/bartolomedelasheras.pdf

Nieto Vélez, Armando, La acción del clero, Comisión Nacional del Sesquicentenario de la Independencia del Perú, Colección Documental de la Independencia del Perú, tomo XX, 2 vols. Lima 1971-1972.

"El arzobispo Bartolomé de las Heras y la independencia del Perú", en Revista Teológica Limense (Lima), VI, 1972, pp. 223233.

_. Antología de la independencia del Perú, edición preparada por Félix Denegri Luna, Armando Nieto Vélez y Alberto Tauro con la colaboración de Luis Durand Flórez. Lima, Comisión Nacional del Sesquicentenario de la Independencia del Perú, 1972.

_. "San Martín y el arzobispo Las Heras", La Prensa (Lima), domingo 26/2/1978, p. 21.

"Aspectos históricos de las relaciones Perú-Santa Sede", Revista Peruana de Derecho Internacional, vol. 46, 1996, pp. 35-49.

—_ "La figura episcopal de Bartolomé de las Heras". Diócesis de Huacho. Una Iglesia joven con una rica historia. 50 años de servicio pastoral. Huacho, 2008, pp. 215-224.

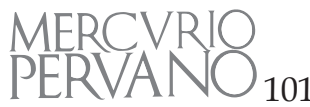


_ , "La campaña literaria fidelista y antinapoleónica en el Perú", en La causa de la emancipación del Perú. Testimonios de la época precursora 1780-1820. Actas del simposio organizado por el Seminario de Historia del Instituto Riva-Agüero. Lima, Pontificia Universidad Católica del Perú, 1960, pp. 36-48.

— Contribución a la historia del fidelismo en el Perú (1808-1810). Lima, Pontificia Universidad Católica, Instituto Riva-Agüero, 1960.

_ _, "Notas sobre la actitud de los obispos frente a la independencia peruana", Boletín del Instituto Riva-Agüero, 8 (1969-1971), pp. 366-370. Reeditado en Documenta. Órgano del Arzobispado de Lima, 4, 1971, pp. 40-149.

Puente Candamo, José Agustín de la, San Martín y el Perú: planteamiento doctrinario. Lima, Lumen, 1948.

Macera, César F., San Martín, gobernante del Perú. Buenos Aires, H. Matera, 1950.

Vargas Ugarte, Rubén, El episcopado en los tiempos de la emancipación sudamericana. Lima, Imprenta Gil, 1962.

_., Historia de la Iglesia en el Perú. 5 vols., Lima, Imprenta Gil, 1953-1961. 